\title{
LEARNING EXPERIENCE ANALYSIS OF EFFECTIVE ENGLISH COURSE CONVERSATION YOUNG LEARNERS IN WEEKLY MEETING PROGRAM
}

\author{
Kresna Rahma Aji ${ }^{1}$, Kifti Halimah Islami, and Yudha Pambudi Wibowo \\ petapabesi@gmail.com, kiftihalimahislami@gmail.com, yudhawibowo65@gmail.com \\ Post-Graduate Program of Semarang State University, Effective English Conversation Course \\ Kudus, SMP N 2 Karanganyar, Kab. Pekalongan
}

\begin{abstract}
As foreign language, English has role to access knowledge for our young learners. It should be the purpose of three kinds of education, such formal, non-formal, and informal education. This descriptive qualitatve analysis research is done in a nonformal English language institution named Effective English Conversation Course, Kudus, in Basic Class 62nd period. With its objectives to provide meaningful description, this research reveals the learning experices of based year selected young learners of EECC from 17 learners in 'Weekly Meeting Program' held on Saturdays, as research's respondents. After giving the opened question questionnaires, the answers from the young learners are taken into abstracted indicators of four learning theories: behaviorism, cognitivism, constructivism, and humanism. Then the data is validated through involving two different observers conducting 5 time observations to provide meaningful interpretation. The findings describe the young learners' learning experiences through the use of humanistic and constructivist approach; and rarely experience the use of behaviorism and cognitivism. Later, the findings of this analysis research may be used as one of issues in young learners' learning experiences, which currently huge attention exists on formal education institution.

Keywords: EECC Young Learners, Learning Experience
\end{abstract}

\section{INTRODUCTION}

Since English as a Foreign Language, meaning the language is not primary means of communication. Kachru (2003) in John Robert Schmitz views the world as being divided into different circles: the inner, outer, and expanding circle. He also defines each circle, such as: firstly, the outer circle is made up of post-colonial countries which English though not the mother tongue, has for a significant period of time played an important role in education, governance, and popular culture; the inner circle, which English is spoken as the primary language; and the last is expanding circle, where English is not spoken and does not have special places of administrative status but it is recognized as lingua franca (Kachru: 1995). The English is taught at school and only learnt in short occasion. However, English is used only to access knowledge for learners. Nicoleta BOTEZ (2015) argues that all kinds of rapid changes are imposing the use of English language to be an essential tool for the good run of any kind of social, economic and cultural activity.

To realize its EFL language purposes, currently language is learnt on three different educational environment: formal, informal, and non-formal education. Claudio Zaki Dib (1988) defines formal education as a systemic, organized educational model, structured and administered 
according to a given set of laws and norms and has rigid curriculum as its purposes, content and methodology. This system refers to schools where English is taught as subject lesson. In other hand, Claudio also sees same features on non-formal education although some features is probably absent. In this non-formal education, the realization is in the form of the existence of courses, such as Effective English Conversation Course. Meanwhile, the last educational system is informal which stands on position in which education does not necessarily include the objective and subjects; and usually encompassed by the traditional curricula by aiming the students as much as the public at large and imposes no obligation whatever their nature (Claudio Zaki Dib. 1988). This third educational system does not appear in our environment since English sees as expanding circle or English as Foreign Language.

EECC, as non-formal educational institution, has purpose to guide its learners to access knowledge through the use of oral spoken English. The course has heterogeneous learners consisting fifth grade of elementary schools until adulthood aged learners. The classes ignore the students' pedagogy stage and concerns on their language level which is divided into 'basic class', and 'training class'. The sequences of each class begun from giving grammatical material comprehending in 'main class'; and then continued to practice all their material comprehension in 'tutorial class'; and in the end of each week, on Saturdays, both classes are joint in a program called 'Weekly Meeting'.

The study analyzes and describes the learners' experiences from aspects of beneficial teacher role and learning context limited only for the young learners of EECC in learning period of BC 62.

\section{LITERATURE REVIEW}

The aspects observed and analyzed of Weekly Meeting program related to English as foreign language education are believed to learn the language through these paradigms: behaviorism, cognitivism, constructivism, and even humanism which may be seen from teacher roles to intervene, to facilitate, to set the habit, or to be the model of language. Then, its learning context are believed to be: based genre, specific purpose, or contextual learning.

In weekly meeting program, the participants come from heterogeneous ages. It is probably assumed to have problem since the participants bring different pedagogical development but the program itself gains considerable attention from the young learners. They do not only come and sit but also participate orally to use the language

Behaviorism

Seeing language as a set of habit, the teaching technique is mostly exact pattern based drilling. The role of teachers is - forging the learners; and is believed teachers are the only way to learn the language. It can be seen through the learning rigidly context designed to follow and often seems unnatural.

\section{COGNITIVISM}

Believing that learners have their own potential called zone of proximal development. The dominant aspects of the paradigm involve the interaction between mental components and the information is processed through this complex network (Neiser, 1967). The existing knowledge inside of learner's thought can be developed by giving more challenge but not too broad for them to understand. When the learners learn, they will actively create structures determining their own concept and the environment (McEntire, 1992). Thus, the role of teachers in this case is to facilitate them create their structures. 
The notion of existing knowledge for cognitivism must be clarified in EFL. Because the language is not used for daily life, then the rising question dealing with the kind of knowledge is - whether this knowledge related to any relevant real knowledge or the knowledge about the language itself.

\section{CONSTRUCTIVISM}

Constructivism is seen as part of educational thought (Egan, 1984) and currently is used to construct people make sense their own experience. By means of experience here is the learners exchange, access, and share among their knowledge. They experience how to deliver, confirm, ask, argue, explain, describe any existing knowledge they have and develop their knowledge through the use of language.

In this case, the language has function of mean instead of taught material. The role of teachers, in other hand, is to facilitate any exchange, access, and share among the learners.

The context of learning is not limited on the material of language elements, however it is far broad and taken from the learners' experiences.

\section{HUMANISM}

This paradigm believes that learning process should be coming from inside of the learners since everyone is unique. It is also believed that learning progress should be non-threatening. The role of teachers become partner or peer to learn, access, gain, share, and exchange knowledge. Through this way, the learners will get their self-actualization. .

The Learning Period of EECC

The system of this non-formal education is by providing three month learning term for a period. In this analysis only focuses on the young learners of Basic Class of the current on-going period, BC 62, started from December 2016 until the late of February 2017. The program actually has six day class schedule but every Saturday, they are required to join Weekly Meeting program.

\section{The Young Learners of EECC}

Young learners are not only learners under 10 year-old. But it also encompasses adolescence, or pupils, between 12 - 19 year old (Susan B. Bastable and Michelle A. Dart, 2014). The young learners also can be seen from their educational levels, in which, now days they need to have 12 year of studying until Senior High School.

\section{The Weekly Meeting Program}

Weekly meeting, WM, is a program originally purposed to facilitate the learners using English. Designed to have ceremonial and a resting session, where the learners socialize through the use of spoken English.

The program is started by having opening ceremonial guided by master or mistress ceremony to deliver the further sequences of the agenda. Below is the table showing the agenda of Weekly Meeting program. 
Table 1. The Sequences of Weekly Meeting by MC

\begin{tabular}{|c|c|c|}
\hline \multicolumn{2}{|c|}{ Sequences } & \multirow{2}{*}{ Description } \\
\hline Order & Agenda & \\
\hline 1 & Reciting Al-Qur'an & $\begin{array}{l}\text { Three participants required to read Al-Qur'an and its } \\
\text { translations. }\end{array}$ \\
\hline 2 & $\begin{array}{l}\text { Initial Speech from } \\
\text { EECC staff. }\end{array}$ & One tutor delivers a welcoming speech. \\
\hline 3 & $\begin{array}{l}\text { Moderated speech } \\
\text { by presenters } \\
\text { followed by question } \\
\text { session. }\end{array}$ & $\begin{array}{l}\text { Three or more students deliver their speech based on their } \\
\text { prepared article. } \\
\text { The article is freely composed. } \\
\text { Continued by asking - answering questions. }\end{array}$ \\
\hline 4 & $\begin{array}{l}\text { Speech from EECC } \\
\text { Kudus director. }\end{array}$ & A speech from the director of EECC Kudus. \\
\hline 5 & Resting & $\begin{array}{l}\text { Performing various resting agenda. It can be also } \\
\text { gathering, party, hanging out, and etc. }\end{array}$ \\
\hline 6 & Closing & Ending the activity. \\
\hline
\end{tabular}

The activity involves 6 up to 8 total numbers of teachers and tutors of EECC. The agenda itself is held about two hours and thirty minutes long. During the agenda, the presenters deliver their article which had been composed in the beginning of the learning period.

The job descriptions of the tutors, based on one of the tutors' explanation are to be: adjudicators and facilitators of Weekly Meeting (Ana Kholidaziya. 23). It is also noticed before beginning the program, the given role students need to be prepared practically two days before that program held on every Saturdays (Masrul Abrori. 20).

The most questionable agenda is the resting session. Since it was expected only having beverages after all sequences of the agenda. However, it is clarified by another tutor that resting session expected to have the students practicing their language through community interaction set into various performing and gathering activity (Wijaya Putra Maulana. 20).

\section{METHOD}

This research has purpose to analyze the young learners' learning experience in Weekly Meeting program was done in $17^{\text {th }}$ of December, 2016. In the research, there was a need to collect the data through questionnaire. There are 12 questions of the questionnaire to reveal learning experiences from the students: learning context and their teacher roles.

To spread the questionnaire, an assistance from the gatekeepers is needed. They have important role to gather the data since having access to the students; and to prevent the correspondents' suspicious feeling toward the given questionnaire.

The questionnaires are given to 12 - 19 years old learners and still have status as learners of formal institution, maximum is Senior High School with 17 year old maximum. Then, it is only gained 9 qualified respondents based on the given conditions of young learners. Those 9 young learners are aged from 13 until 17 with educational background Junior until Senior High Schools, consisting 5 male and 4 female learners. 


\section{Gaining Access}

To get the access, three author composed research is including one of the teachers. Then, after that is continued by having arrangement with the director to hold an analysis towards the learners' learning experiences.

\section{Respondents}

The respondents are selected based on their age written on the given questionnaires. They are only taken based on three qualification: $12-19$ year old; still under learning period until maximum third grade of Senior High School; and maximum 17 year-old by third grade of Senior High School.

The selected respondents later are required to fill the questionnaire guided by the gatekeepers to prevent misunderstanding or suspicious action toward the questionnaires.

\section{Observation}

By providing two observers taken from one of the researchers and the gatekeeper, the observation seeks the frequency of emerging features representing the criteria of the paradigms started done for both the teachers and the students from 12 emerging features. These features have $1-4$ scale representing the frequency to interpret the emerging learning experience. The observation is done in five times, one each week scheduled from $4^{\text {th }}, 11^{\text {th }}, 18^{\text {th }}, 25^{\text {th }}$ of February 2017, and $4^{\text {th }}$ of March 2017.

The results of both observers will be calculated to get average score of the frequency, then is interpreted as: behavior learning experience $(1-1.75)$, cognitive learning experience $(1.76-$ $2.51)$, constructive learning experience $(2.52-3.27)$, and humanist learning experience $(3.28-$ 4.00)

\section{Questionnaire}

The questionnaire has 12 questions and is typed by using English in the form of open questions. It is used to get the learners' learning experience then later will be interpreted based on indicators abstracted from 4 learning theories.

While answering the questionnaire, the expectation that some students perhaps have difficulty to answer it due to their English proficiency affected by their age is prevented by the role of gatekeepers.

\section{Gatekeepers}

There are four gatekeepers invited to help gaining the data from the questionnaire. All of the gatekeepers are the EECC's tutors and teachers. At the beginning, every one of them was explained about the purpose of the research; and the use of questionnaire.

Related to the previous session of questionnaire explanation, to prevent the learners' confusion, the need of each question intention of the questionnaire needed to be explained. After explaining the intention of each question, gatekeeper took over the questionnaire and delivered the questionnaires to them.

The gatekeepers are also given freedom when the respondents are having difficulties to answer by using English, they are welcome to answer it by using bahasa Indonesia; because the purpose is to get the data of their learning experiences. 


\section{Technique of Analyzing Data}

The data taken from the questionnaires are in the form of students' sentences, expressing their learning experiences during joining Weekly Meeting program. Each sentence of the students on the given questions will be interpreted based on the indicators abstracted from four learning theories or approaches: behaviorism, cognitivism, constructivism, and humanism seen from two aspects, teacher or tutor roles, and learning context.

The abstraction of 4 learning theories buildup 39 indicators of learners' experiences, labeled A until PP. These indicators are divided into two division: learning experiences related to the teacher roles, and related to learning context itself.

All the learners' answer will be collected and analyzed by using descriptive qualitative to provide meaningful and detail description of their learning experiences through the indicators. The higher number of indicators of a certain learning experience group will be considered as experienced learning paradigm by the learners.

The observation findings on the emerging features is used to validate the findings found by using questionnaire done by relating the interpreted meaning of the data to conclude whole the learner learning experiences.

\section{FINDINGS AND DISCUSSION}

From the analysis, related to the number 1 labeled questions, 7 learners' answers indicate Alabeled indicator, teachers as model; one student also argued D labeled indicator, teacher sociability, which means teacher is also friend. However, two answers cannot be interpreted since no keyword indicating indicators of abstracted learning theories. From this data, it is understandable that until now, no matter what learning theories is, the role of teachers is still being the model for the learners. However, only a few of them probably exceed it and becomes a good friend of the learners.

The second questions reveals two E labeled interpreted answers from the students, and $4 \mathrm{~B}$ labeled interpreted and one D labeled interpreted answers. Meanwhile, only one answer cannot be interpreted. This condition shows that the learning approaches appears are constructivism and humanism. It can be understood from the answers that: the students perform their existing knowledge during the program while the teachers offer help to facilitate among the students. During this activity, the learners construct their knowledge but the knowledge itself is not English grammatical patter knowledge, instead it is real existing knowledge from the students previously composed inside of their articles.

One of the students' answer indicate D labeled indicators, which means the teachers and tutors encourage the students humanistically to participate into the activity. In another hand, E labeled indicators show that there is still a need for the teachers and tutors to manage and structure the program during this ongoing process.

Third question, related to learning context division, is mostly answered $\mathrm{F}$ labeled indicators by the 8 students. It informs that the students' learn new knowledge from their experiences during the class. However, one of the students' answer cannot be interpreted. 
The fourth question is mostly answered by eight $\mathrm{J}$ labeled indicators. But one of the students' answer cannot be interpreted. It believes that the learners learn through constructing new knowledge through their learning experiences. It fits on constructivism and humanistic learning theories. But one of the answers' of the students cannot be interpreted.

There are two L, one $\mathrm{M}$, and $6 \mathrm{~N}$ labeled answers based on the indicators in the fifth questions, it shows the students perform their existing knowledge, interact with the community members, and passively gaining knowledge from the community members.

In the sixth questions, 3 answers from three students cannot be interpreted. But there are five $U$ and $3 \mathrm{P}$ labeled answers from the rest of the students. Those labeled answers indicate the student feeling free in the program as well as to perform their existing knowledge.

On the next question, five students express that they can apply their English interaction practices to the community, as indicated by $\mathrm{W}$ labeled answers. Three other persons show that they can apply their personal learning steps, indicated by Y labeled answers. And one of them can apply self-evaluation as indicated by $\mathrm{X}$ labeled answer.

The eight questions are answered by all students through $\mathrm{CC}$ labeled questions plus two BB labeled questions. The condition shows most the students can apply personal learning ways and two of them can apply self-evaluation.

The next questions gained nine EE labeled questions which shows the students feel comfortable in non-threatening learning situation. However, one of the students express their boredom since in her experience sometimes turns into boring condition, indicate $\mathrm{d}$ by FF labeled answer.

The GG labeled answers appears on all students in tenth questions, indicating positive social interaction effect from the community through the use of the language.

The eleventh questions shows two kinds of students' answers labeled as JJ, 3 answers from three students; and KK, 6 answers from six students. The condition can be described that they can get new knowledge through positive social interaction by using the language.

The last questions shows two kinds of students' answers also, labeled as OO, 6 answers from six students; and PP, 4 answers from 4 students. The condition informs that the learners experience social interaction effect and trigger personal need awareness reasons.

From the findings, there are 88 students' answers indicating humanistic learning approaches and 82 answers indicating constructivism learning approach. It is possible since the use of language in the program is intended to let the students practice their English to gain access. Gaining access means that the learners experience how to ask, deliver, exchange, socialize, interact, and communicate using the language into their existing knowledge. These experiences are also confirmed by the respondents as their learning experiences in the program.

The knowledge discussed here is not the knowledge of language elements, such as grammatical pattern rule, kinds of genre, language features, or the other English lesson material. Instead, the knowledge is in the form of their real world reality embodiment found in their article. After that, the learners access among their knowledge and construct their new knowledge through experiences. 
In this analysis, all the sequences of the program lead the students experiencing and constructing their knowledge by having self-awareness, self-knowledge construction, self-learning steps, social interaction to the community, socialize to the community, exchanging knowledge inside of the community. In this case, the role of the students are not fully set by the teachers and tutors, meanwhile the students their selves put themselves into each role of social interaction with the teachers. It is something that can be achieved through the use of humanistic approach; and the language is not seen as lesson material but instead meant of socializing.

The interpreted data above is validated by the average score of emerging features done by two observers: 3.52 from first observer and 3.3 from second observer, 3.4 in average score, indicating humanist learning experience.

In term of non-formal educational institution, the course plays its role to provide non-threatening learning English area which seems cannot be done smoothly at formal schools. The reason is because the course, based on the analysis, provides and sees the language as meant to socialize and access the new knowledge. In this non-formal education also develops flexible condition which is not bind rigidly to formal education curriculum which mostly only has short and limited time of studying and using the language as lesson material.

It may be different when is compared to formal institution which probably has higher difficulties to promote humanistic since the use of language seen as lesson material. Another difficulty is that English at schools is only taught with 90 minute learning time with maximum two meetings per week, covering two until four learning time period.

\section{CONCLUSION AND SUGGESTION}

From the findings and discussion above, it can be seen and concluded also that non-formal institution also plays important role in providing better students' learning experiences based on the analysis results. Secondly, existing knowledge and new knowledge meant to learn English will have better learning experiences when it is taken from the learners' real world instead of learning grammatical patter rules, genres, and other language unit lesson. The most experienced learning experiences by the students is humanistic which provides, facilitates, and allows the young learners to socialize, access, exchange, perform, interact, and communicate using the language. Important to remember that the embedded learning experience has high possibility emerging only in Weekly Meeting program, as one of learning schedules from total six day classes.

Some suggestions are addressed for better and further research: firstly, since this analysis study only uses questionnaire and observation designed by the researchers and gatekeepers, there will be a need of better collecting data instrument to investigate related issues on young learners' learning experiences; secondly, this research can be used to trigger any other methodology of research in the field of young learners' learning experiences; since the program is one of six day class schedules, there will be high possible strong relationship among all learning paradigms before it comes into emerging learning experience in WM; and the last one, the findings in this research can be further investigated and denied by any scientific research on the same field. 


\section{REFERENCES}

Bastable, B. Susan. (2014). Developmental Stages of the Learner. Chapter 5. (C) Jones and Bartlett Publisher.

Clint, Grider. (1993). Foundation of Cognitive Theory: A concise Review.

Dib, Zaki Claudio. (1987). Formal, Non-Formal and Informal Education: Concepts/Applicability. Brazil: Institute of Physics. University of Sao Paulo.

Ertmen, Peggy A. Newby, J. Timothy. Behaviorism, Cognitivism, Constructivism: Comparing Critical Features from an Instructional Design Perspective.

Nation, Paul. The Role of the First Language in Foreign Language Learning. Asian EFL Journal.

Richard, J. C., \& Rodgers, T.S. (2014).Approaches and Methods in Language Teaching. Cambridge University Press. ISBN: 978-1-1-7-67596-4

Schimtz, John Robert. (1982, 1985). Looking under Kachru's Three Circles Model of World Englishes: the Hidden Reality and Current Challenges. Brazil: Universidade Estadual de Campinas: Sao Paulo.

Stein, Gabriele. EFL Dictionaries, the Teacher and the Students. JALT Journal, Volume 11. No. 1

Taber, Ketih S. (2011). Constructivism as Educational Theory: Contingency in Learning and Optimally Guided Instruction. Jaleh Hassaskhah (Ed). ISBN: 978-1-61324-580-4 2011

Tomic, Welko. Behaviorism and Cognitivism in Education. Netherland: The Open University Social Sciences Departement. 